\title{
Triagem estendida: serviço oferecido por uma clínica-escola de Psicologia ${ }^{1}$
}

\author{
Eliana Herzberg ${ }^{2}$ \\ Débora Chammas \\ Universidade de São Paulo, São Paulo-SP, Brasil
}

\begin{abstract}
Resumo: Este artigo objetiva apresentar e discutir uma experiência de atendimento em triagem psicológica realizada em uma clínica-escola de psicologia de São Paulo-SP. A proposta triagem estendida, em oposição à tradicional, podia ocorrer em até seis entrevistas, seguindo referencial psicanalítico. Foram atendidos dez participantes que não haviam conseguido vaga para a triagem semanal da clínica. A análise incluiu aspectos tais como adesão, queixa manifesta versus latente, desenvolvimento do processo, expectativas em relação ao atendimento e encaminhamentos. Concluiu-se pela viabilidade e vantagens desta forma de recepção de clientes em uma realidade carente de recursos de atenção à saúde.
\end{abstract}

Palavras-chave: serviços de saúde mental, acesso aos serviços de saúde, psicoterapia breve, aconselhamento.

\section{Extended screening: service delivered by a psychological clinic}

\begin{abstract}
This article aimed to present and discuss a psychological screening process carried out at a psychological outpatient clinic in São Paulo-SP. The extended screening service based on a psychoanalytical reference and opposed to the traditional one, could be carried out in up to six interviews. Ten participants who had not managed to be included in the weekly screening were studied. The analysis included adherence, manifest versus latent complaints, process development, expectations regarding attendance and referrals. The conclusion is that this form of attending clients is viable and present advantages in a reality devoid of health services and resources.
\end{abstract}

Keywords: mental health services, health services accessibility, brief psychotherapy, counseling.

\section{Recepción estendida: servicio ofrecido por una clínica-escuela de Psicología}

Resumen: El objetivo desde artículo es el de presentar y discutir la recepción estendida, realizada en una clínica-escuela de psicología de São Paulo-SP. La propuesta de la recepción estendida, en oposición a la recepción tradicional, podía ocurrir en hasta seis entrevistas, siguiendo un referencial psicoanalítico. Fueron atendidos diez participantes que no habían conseguido un lugar en la inscripción semanal en la clínica. El análisis incluyó adhesión, queja manifiesta versus latente, desarrollo del proceso y las expectativas y orientaciones. Se llegó a conclusión, tanto por la factibilidad como por las ventajas de esta forma de recepción de clientes, principalmente en una realidad carente de recursos de atención en la salud.

Palabras clave: servicios de salud mental, accesibilidad a los servicios de salud, psicoterapia breve, aconsejar.

$\mathrm{O}$ atendimento propiciado por clínicas-escola, também denominadas serviços-escola, a partir do $12^{\circ}$ Encontro de Clínicas-Escola do Estado de São Paulo em 2004 (Melo-Silva, Santos, \& Simon, 2005) tem sido alvo crescente de pesquisas e debates (Ancona-Lopez, 1995; Herzberg, 1996, 2007; Macedo, 1984; Melo-Silva, Santos, \& Simon, 2005; Romaro e cols., 2005; Silvares, 2006). Por estarem ligadas ao contexto da universidade, aos eixos de desenvolvimento de pesquisas, formação de alunos e serviços de extensão à comunidade, podem constituir-se em "laboratórios de excelência". Neste sentido, investigações que busquem desenvolver meios de simultaneamente estender o atendimento a um maior número de pessoas e manter sua qualidade podem ser de grande valia. Dado o escopo deste trabalho, serão focalizadas algumas questões relacionadas ao funcionamento de clínicas-escola,

1 Apoio: FAPESP. As autoras agradecem a colaboração da Equipe Técnica da Clínica Psicológica Dr. Durval Marcondes do Departamento de Psicologia Clínica do Instituto de Psicologia da Universidade de São Paulo, onde a pesquisa foi realizada. O presente trabalho constitui a apresentação e discussão parcial dos dados obtidos em pesquisa de iniciação científica.

2 Endereço para correspondência:

Profa. Dra. Eliana Herzberg. Universidade de São Paulo. Instituto de Psicologia. Departamento de Psicologia Clínica. Av. Prof. Mello Moraes, 1721. CEP: 05508-030. São Paulo-SP, Brasil.E-mail: eherzber@usp.br embora o fato de pertencerem ao Sistema Único de Saúde demande a discussão de uma série de outras.

Os atendimentos oferecidos em clínicas-escola de psicologia incluem, entre outros, triagem, psicodiagnóstico, psicoterapia individual, de casal, familiar, atendimentos preventivos e grupos de espera (Guerrelhas \& Silvares, 2000; Melo, 1999). A triagem constitui, muitas vezes, a "porta de entrada" para o encaminhamento dos clientes às outras modalidades de atendimento, tendo, assim, relevante papel em uma clínica, dada sua função de escuta inicial, avaliação e encaminhamento. Como ocorre na maioria das instituições de saúde, a demanda é geralmente maior do que o número de vagas oferecido, havendo rotineiramente pessoas que não conseguem atendimento (Chammas \& Herzberg, 2006; Guerrelhas \& Silvares, 2000; Herzberg, 1996; Melo, 1999; Salinas \& Santos, 2002).

Algumas pesquisas apontam resultados sobre o uso da triagem como atendimento clínico inicial (espaço de intervenção), com diferentes abordagens teóricas, utilizando um ou mais encontros (Ancona-Lopez, 1995; Ancona-Lopez, 2005; Agostinho, 2003; Aguirre, 1987; Isaco, Gil, \& Tardivo, 2004; Salinas \& Santos, 2002). Salinas e Santos, por exemplo, realizaram e interpretaram a triagem por meio de referencial psicanalítico em contexto institucional, a qual denominaram Atendimento Imediato de Triagem, apontando que esta 
deve ser mais do que a mera coleta de dados para subsidiar um encaminhamento, podendo constituir uma proposta de intervenção em si mesma. Encontramos eco, nesse mesmo sentido, em autores uruguaios tais como Bonomo, Dominguez e Tortorella (2002) que, ao tratarem de intervenções nos diferentes âmbitos da área da saúde mental, enfatizaram a importância das entrevistas de triagem abarcarem dois processos: a escuta do saber que o cliente tem acerca de si mesmo e o parecer que o psicólogo pode emitir. Salientaram que a entrevista de recepção deveria possibilitar uma aproximação diagnóstica, por meio de uma clarificação da problemática apresentada, e ainda uma elaboração conjunta e hierarquizada do saber do consultante, resultando em um encaminhamento e orientação, no sentido abrangente do termo. Triagens interventivas também têm sido alvo de discussões no grupo de trabalho Atendimento Psicológico nas Clínicas-Escola da Associação Nacional de Pesquisa e Pósgraduação em Psicologia (ANPEPP).

Tendo como temática as entrevistas iniciais, outros pesquisadores concordam quanto à necessidade frequente de abreviar a condução de um processo que à primeira vista assumiria as características de intervenção a longo prazo. Não se trata de concluir que o problema apresentado seja de simples resolução ou mesmo que o profissional não esteja detectando um aspecto mais profundo. Trata-se de promover oportunidade delimitada de expressão e possibilitar ao usuário algum tipo de retorno, mesmo que limitado, por parte de um profissional psicólogo (Arzeno, 1993; Herzberg, 1996; Ocampo \& Arzeno, 1979/1981; Verthelyi, 1989).

A prática tem revelado que, no intervalo de tempo decorrido entre a inscrição na clínica e o atendimento propriamente dito, o cliente pode percorrer uma longa e demorada trajetória. Não raramente, ao ser atendido, o usuário demonstra que tanto a queixa apresentada quanto sua motivação já são distintas das que originalmente o impulsionaram à busca pelo serviço (Salinas \& Santos, 2002). Alguns dos fatores que provocam essa situação indesejável são difíceis, se não impossíveis, de se contornar. Como escola, a clínica fica geralmente submetida ao calendário letivo da universidade e ao tempo necessário para a formação do aluno-estagiário na aprendizagem de diversas modalidades. A recepção mais estendida ao cliente permite aprofundar os motivos que o levaram a procurar a clínica e verificar o engajamento com o atendimento, o que pode contribuir para a redução de desistências e aumentar o número de pessoas contempladas pelo Serviço, considerando-se que há um melhor aproveitamento da relação encaminhamentos/vagas (Herzberg, 1996).

A experiência em triagem de entrevista única indica que com frequência o cliente não tem idéia do que seja um atendimento psicológico e não chega, necessariamente, com a expectativa de que este seja mais prolongado. Às vezes, expressa dúvidas sobre questões de desenvolvimento próprio ou dos filhos; outras vezes, está vivendo um momento particularmente crítico em sua vida; ou, ainda, afirma ter sido encaminhado por terceiros mas não tem muito claras as razões destes (Chammas \& Herzberg, 2006; Salinas \& Santos, 2002, Souza Filho, Oliveira, \& Lima, 2006). Quanto às queixas, podem ser encontradas discrepâncias entre as queixas manifestas - motivos aos quais o cliente se refere explicitamente como aqueles que o levaram a buscar atendimento psicológico - e as queixas latentes - motivos profundos, muitas vezes não-conscientes, que o levaram a procurar este mesmo atendimento (Ocampo \& Arzeno, 1979/1981).

Torna-se imperioso propiciar aos clientes formas de atendimento mais ágeis, sem substituir as já consagradas, que possam contornar alguns dos inconvenientes existentes no funcionamento das clínicas-escola. Ademais, a impossibilidade de suprir a grande demanda e as crescentes dificuldades financeiras e de locomoção na cidade compõem fatores que remetem à ampliação dos tipos de atendimento e à otimização dos recursos disponíveis com base na reflexão sobre a organização institucional.

Visitas a centros de atendimento e formação profissional que prestam serviços à comunidade, intensificaram a convicção das autoras de que é necessário ampliar as formas de atendimento psicológico oferecidas em clínicas-escola. O projeto "Problemas Conjugais: Atendimento em Psicoterapia Breve", em andamento na Clínica Psicológica do Instituto Sedes Sapientiae de São Paulo (Hegenberg, 2004), e as concepções de dois Serviços da Clínica de Tavistock em Londres, visitados em 2002, a saber, o Serviço de Consultas para Jovens (Young People's Consultation Service) e o Serviço para Pais (The Parents Service), tiveram grande influência na constituição da proposta de triagem estendida (TE) oferecida pela Clínica Psicológica Dr. Durval Marcondes do Instituto de Psicologia da Universidade de São Paulo (USP). Estudos como os de Fiorini (1973/1978), Hegenberg (2004), Simon (1989) e Wolberg (1965/1979) sobre o desenvolvimento de formas de atendimento breve, em vários contextos e com referencial psicanalítico, deram substrato à proposta.

A proposta consistiu de intervenção em curto prazo com objetivos delimitados, dentre os quais explicitar o motivo da procura, verificar, em termos práticos, a viabilidade do atendimento buscado e suprir, mesmo que pontualmente, a alguma(s) das demandas destes usuários. Visou oferecer atenção ao cliente e também estender a um maior número deles a possibilidade de recebê-la. A fim de pesquisar as características e a eficácia desta modalidade, realizaramse, simultaneamente, atendimentos e um levantamento de expectativas de clientes em sala de espera (Tognotti \& Herzberg, 2004).

O objetivo geral deste artigo é apresentar e discutir uma experiência de atendimento a clientes dentro da modalidade triagem estendida. A evolução de dez atendimentos foi descrita incluindo a análise de suas implicações, tanto para os clientes quanto para a clínica-escola prestadora desse serviço à população. As implicações foram analisadas através de indicadores, tais como: adesão às consultas, evolução da queixa, expectativas com relação ao trabalho do psicólogo e desenvolvimento do atendimento e encaminhamentos. 


\section{Método}

\section{Participantes}

Foram atendidos dez usuários do serviço em questão no período de julho a novembro de 2006, o fato de serem excedentes da triagem tradicional da clínica no dia de inscrição regular foi utilizado como critério de inclusão, não houve critério de exclusão.

\section{Instrumentos}

Foram realizadas entrevistas semi-abertas (Bleger, 1974) pautadas em tópicos pré-estabelecidos a serem investigados, tanto o momento como a ordem da investigação variava de acordo com as características do participante. Os tópicos giravam em torno do esclarecimento dos motivos da consulta, partindo da queixa manifesta e buscando a compreensão do eventual conflito, de expectativas em relação a um possível atendimento e de sua viabilidade prática. Buscou-se oferecer acolhimento ao cliente em seu movimento de procura por atendimento psicológico.

\section{Procedimento}

Os dados foram coletados na Clínica Psicológica Dr. Durval Marcondes do Departamento de Psicologia Clínica do Instituto de Psicologia da Universidade de São Paulo. A pesquisadora convidou cada potencial participante (excedente do determinado dia de triagem regular da Clínica) a ser atendido por ela em uma modalidade de atendimento que estava sendo pesquisada. O número máximo de sessões seriam seis, uma por semana, com duração aproximada de cinquenta minutos cada. Informou-lhes também que o atendimento objetivaria esclarecer o motivo da busca pelo serviço, verificar a possibilidade de encaminhamento e sanar eventuais questões e dúvidas que pudessem existir quanto ao atendimento psicológico propriamente dito. Embora houvesse preocupação com o encaminhamento (se fosse o caso) de cada participante, foi explicado que não haveria garantia de continuidade na própria clínica. As entrevistas e os encaminhamentos dados aos participantes foram discutidos em supervisões semanais com a coordenadora do projeto.

\section{Análise de dados}

Os dados são apresentados em forma de tabelas, contemplando a caracterização sócio-demográfica e clínica dos participantes, com as categorias de encaminhamento, e um resumo da evolução de cada processo de triagem estendida.

Foi utilizado o referencial teórico psicanalítico em uma abordagem clínico-qualitativa de pesquisa (Turato, 2003). A análise foi prioritariamente qualitativa, buscando debater características e alcances da triagem estendida.

\section{Aspectos éticos}

$\mathrm{O}$ atendimento em modalidade de pesquisa foi aprovado pelo Comitê de Ética da instituição atendendo aos requisitos de pesquisa com seres humanos, conforme Resolução no 196, de 10 de outubro de 1996, da Comissão Nacional de Ética em Pesquisa. Os participantes assinaram o Termo de Consentimento Livre e Esclarecido que continha esclarecimentos sobre a pesquisa, publicações e o compromisso de sigilo quanto a dados que pudessem permitir sua identificação. $\mathrm{O}$ cliente que não desejasse participar da pesquisa foi orientado a retornar para o sistema de triagem tradicional, tendo em vista que a modalidade de triagem estendida estava sendo realizada em cunho de pesquisa. No entanto, todos os excedentes de triagem aos quais a proposta foi oferecida, aceitaram participar e assinaram o Termo de Consentimento.

\section{Resultados e Discussão}

Na Tabela 1 é apresentada uma caracterização dos participantes quanto ao sexo, idade, estado civil, número de consultas realizadas, origem do encaminhamento e encaminhamento feito ao final do processo. As categorias de encaminhamento ao final foram: (a) externo à psicoterapia ou avaliação médica (externo); (b) interno à psicoterapia (interno, na própria Clínica); (c) finalizado sem encaminhamento (finalizado); (d) abandono (abandono), quando o cliente deixava de dar continuidade sem qualquer tipo de comunicação.

Cabe esclarecer que o encaminhamento externo tem sido usado como alternativa a grande demanda por atendimento que a Clínica apresenta e não consegue suprir, ou nas situações em que a localização do profissional em termos geográficos é mais acessível ao cliente. Tal encaminhamento é direcionado a psicólogos cadastrados na Clínica, que assumiram o compromisso de atender clientes conforme suas possibilidades financeiras. São indicados, em geral, no mínimo dois profissionais a fim de possibilitar escolha ou remanejamento por parte do cliente.

Quanto à variável sexo, o número de participantes foi o mesmo (cinco participantes do sexo feminino e cinco do masculino). Quanto ao estado civil, dos sete participantes adultos um era solteiro, três eram casados e três separados. Três participantes eram menores de idade, sendo a mãe quem procurou a Clínica (em tais casos, os pais, quando acessíveis, foram atendidos).

$\mathrm{O}$ número de consultas em triagem estendida variou conforme a demanda, rumo do trabalho, vínculo e uso do espaço oferecido. Sete participantes utilizaram as seis entrevistas. No caso do Participante 5, houve abandono após a $5^{\text {a }}$ consulta. Cabe mencionar que, em pesquisa follow up realizada a fim de verificar, entre outros fatores, a satisfação dos participantes, este sujeito informou que as consultas tinham sido de grande valia, a despeito de não ter comparecido à última. $\mathrm{O}$ Participante 6 veio com indicação médica para a psicoterapia e apresentou problemática específica. $\mathrm{O}$ trabalho foi breve, girando ao redor do esclarecimento de sua disposição para fazer psicoterapia, para além da indicação médica, e das expectativas e estilos de trabalho psicológicos, 
visto que ele esperava um atendimento "mais objetivo". Entendeu-se, assim, que aprofundar os motivos de sua queixa, naquele momento, seria iniciar efetivamente um processo terapêutico, o que não correspondia aos objetivos propostos pela triagem estendida. De maneira geral, foi alta a adesão ao modelo de atendimento em questão, pois foi aceito por todos os excedentes para os quais foi oferecido e observou-se intensa vinculação dos participantes em relação ao processo.

Tabela 1

Identificação, encaminhamento inicial e final dos participantes

\begin{tabular}{|c|c|c|c|c|c|c|}
\hline Participante & Sexo & Idade & Estado civil & $\begin{array}{l}\text { Número de } \\
\text { consultas }\end{array}$ & Origem do encaminhamento & $\begin{array}{c}\text { Encaminhamento ao } \\
\text { final }\end{array}$ \\
\hline 1 & M & 31 & Casado & 6 & Psiquiatra & $\begin{array}{c}\text { Interno } \\
\text { Psicoterapia }\end{array}$ \\
\hline 2 & $\mathrm{~F}$ & 12 & Solteiro & $\begin{array}{l}6 \text { (1 mãe, } 4 \text { filha, } 1 \\
\text { mãe e filha) }\end{array}$ & Procura espontânea & $\begin{array}{c}\text { Externo } \\
\text { Psicoterapia }\end{array}$ \\
\hline 3 & M & 8 & Solteiro & $\begin{array}{l}7 \text { (2 mãe, 1 pai, } 2 \\
\text { casal, } 2 \text { filho) }\end{array}$ & $\begin{array}{c}\text { Pediatra } \\
\text { Unidade Básica de Saúde, } \\
\text { descontinuou atendimentos } \\
\text { psicoterápicos, encaminhou } \\
\text { para Clínica }\end{array}$ & $\begin{array}{c}\text { Externo } \\
\text { Psicoterapia }\end{array}$ \\
\hline 4 & $\mathrm{~F}$ & 76 & Separado & 6 & $\begin{array}{l}\text { Núcleo de tratamento de obe- } \\
\text { sidade }\end{array}$ & Finalizado \\
\hline 5 & M & 26 & Casado & 5 & Trabalho & Abandono \\
\hline 6 & M & 25 & Solteiro & 2 & $\begin{array}{l}\text { Médico (excluiu alteração hor- } \\
\text { monal ou doença orgânica) }\end{array}$ & $\begin{array}{c}\text { Externo } \\
\text { Psicoterapia }\end{array}$ \\
\hline 7 & $\mathrm{~F}$ & 42 & Separado & 6 & Procura espontânea & $\begin{array}{c}\text { Externo } \\
\text { Psicoterapia }\end{array}$ \\
\hline 8 & M & 40 & Separado & 6 & Procura espontânea & $\begin{array}{c}\text { Externo } \\
\text { Avaliação cardiológica e } \\
\text { psicoterapia }\end{array}$ \\
\hline 9 & $\mathrm{~F}$ & 15 & Solteiro & $\begin{array}{l}6 \text { (1 mãe, } 4 \text { filha, } 1 \\
\text { mãe e filha) }\end{array}$ & Escola & $\begin{array}{c}\text { Externo } \\
\text { Psicoterapia }\end{array}$ \\
\hline 10 & $\mathrm{~F}$ & 63 & Casado & 6 & Procura espontânea & $\begin{array}{c}\text { Externo } \\
\text { Psicoterapia }\end{array}$ \\
\hline
\end{tabular}

Quanto à origem dos encaminhamentos neste grupo, pôde ser observado predomínio daqueles realizados por outros profissionais e/ou instituições, quando comparados ao número de procuras espontâneas. Nos casos em que a procura não foi espontânea, notou-se, tal como o Participante 6 citado acima, que a triagem estendida possibilitou esclarecimento da disponibilidade de dar continuidade a um atendimento. Quanto aos encaminhamentos realizados, um foi interno e sete foram direcionados a psicólogos cadastrados pela Clínica (externo), já o atendimento do Participante 4 foi finalizado sem encaminhamento, por determinação do próprio.

A Tabela 2 apresenta o panorama resumido de cada atendimento de modo a evidenciar a evolução de cada processo - estudo de caso. Os dados foram subdivididos em quatro categorias: (a) queixa inicial; (b) expectativas em relação ao papel do psicólogo ou da psicoterapia e aspectos relevantes da relação que se estabeleceu com o psicólogo; (c) desenvolvimento e evolução do atendimento, que inclui aprofundamento da queixa inicial, eventual acolhimento de outras queixas, compreensão da problemática e discussão de possíveis modos de lidar com essa ou outras intervenções, dentre as quais destacamos as pontuais, ou orientações diretivas, consideradas nos casos de pais que buscavam orientação para lidar com a problemática do filho, bem como quando o próprio cliente solicitava alguma orientação; (d) finalização e/ou observações relevantes, incluindo sensações descritas pelos participantes e interesse pela continuidade do atendimento.

Com frequência, alguma menção foi feita à figura do terapeuta ou às expectativas com relação ao psicólogo e à psicologia de forma geral. As expectativas e a dinâmica da relação com a psicóloga puderam ser elaboradas ao longo dos encontros, em especial no fechamento de cada processo. Mais de um participante afirmou ter, a princípio, receio de receber julgamento ou diagnóstico que o rotulasse. No entanto, surpreendeu-se e revelou satisfação com o fato do atendimento permitir a ele ser ouvido, podendo elaborar discursivamente (conversas, como citado por alguns) suas questões pessoais. 
Tabela 2

Evolução do processo de triagem estendida dos participantes

\begin{tabular}{|c|c|c|c|c|}
\hline Participante & Queixa inicial & $\begin{array}{l}\text { Expectativas e relação } \\
\text { com o psicólogo }\end{array}$ & Desenvolvimento & Finalização e observações \\
\hline 1 & $\begin{array}{l}\text { Irritabilidade, } \\
\text { desconfiança, medo } \\
\text { de perder controle e } \\
\text { vínculos. }\end{array}$ & $\begin{array}{l}\text { Negativas: Receber rótulo } \\
\text { diagnóstico }\end{array}$ & $\begin{array}{l}\text { Trabalho exige estado de } \\
\text { alerta e tensão, modos de } \\
\text { lidar com relacionamentos }\end{array}$ & $\begin{array}{l}\text { Refere sentir-se mais } \\
\text { calmo, desejo de continuar } \\
\text { atendimento com a } \\
\text { psicóloga }\end{array}$ \\
\hline 2 & Tédio, insatisfação & Alta expectativa de ajuda & $\begin{array}{l}\text { Dinâmica familiar, } \\
\text { ausência do pai }\end{array}$ & $\begin{array}{l}\text { Indecisão quanto ao } \\
\text { encaminhamento }\end{array}$ \\
\hline 3 & $\begin{array}{l}\text { Medos, agitação } \\
\text { (traumatismo craniano, } \\
\text { sem lesão cerebral) }\end{array}$ & Positiva & $\begin{array}{l}\text { Sentimento de culpa, } \\
\text { colocação de limites (pais), } \\
\text { papéis familiares }\end{array}$ & $\begin{array}{l}\text { Referiram diminuição dos } \\
\text { medos }\end{array}$ \\
\hline 4 & $\begin{array}{l}\text { Orientação para } \\
\text { tratamento de } \\
\text { obesidade }\end{array}$ & Desconfiança & $\begin{array}{l}\text { Envelhecimento, carência } \\
\text { afetiva, procura por novas } \\
\text { motivações }\end{array}$ & $\begin{array}{l}\text { Sente-se apta para } \\
\text { seguir sem atendimento } \\
\text { psicológico }\end{array}$ \\
\hline 5 & Depressão, insônia & $\begin{array}{l}\text { Receber rótulo } \\
\text { diagnóstico }\end{array}$ & $\begin{array}{l}\text { Preocupação com escolhas, } \\
\text { dificuldades profissionais/ } \\
\text { familiares }\end{array}$ & $\begin{array}{l}\text { Relata que o processo o } \\
\text { ajudou }\end{array}$ \\
\hline 6 & Dificuldades sexuais & $\begin{array}{l}\text { Encaminhamento para } \\
\text { profissional experiente }\end{array}$ & $\begin{array}{l}\text { Relacionamento atual com } \\
\text { namorada, desemprego }\end{array}$ & $\begin{array}{l}\text { Encaminhado por } \\
\text { estar decidido a fazer } \\
\text { psicoterapia }\end{array}$ \\
\hline 7 & Ansiedade, agitação & $\begin{array}{l}\text { Positiva (presenteou a } \\
\text { psicóloga) }\end{array}$ & $\begin{array}{l}\text { Mapeamento dos pontos } \\
\text { nodais de dificuldades, } \\
\text { formas de lidar com elas }\end{array}$ & $\begin{array}{l}\text { Refere diminuição da } \\
\text { intensidade da ansiedade }\end{array}$ \\
\hline 8 & $\begin{array}{l}\text { Insônia, falta de ar, } \\
\text { sensação de pânico, } \\
\text { crise }\end{array}$ & $\begin{array}{l}\text { Dúvidas quanto a poder } \\
\text { ser ajudado por psicóloga } \\
\text { jovem e mulher }\end{array}$ & $\begin{array}{l}\text { Questionamento de } \\
\text { antigos valores, novos } \\
\text { posicionamentos }\end{array}$ & $\begin{array}{l}\text { Expressou desejo de } \\
\text { continuar o atendimento } \\
\text { com a psicóloga }\end{array}$ \\
\hline 9 & $\begin{array}{l}\text { Desempenho escolar } \\
\text { insatisfatório }\end{array}$ & $\begin{array}{l}\text { Mãe preocupava-se } \\
\text { se a filha rejeitaria o } \\
\text { atendimento psicológico }\end{array}$ & $\begin{array}{l}\text { Dificuldades familiares e } \\
\text { de relacionamento social, } \\
\text { não conhecia o pai }\end{array}$ & $\begin{array}{l}\text { Filha forma vínculo com } \\
\text { a psicóloga (dá objeto de } \\
\text { valor pessoal) }\end{array}$ \\
\hline 10 & $\begin{array}{l}\text { Tristeza, sensação de } \\
\text { vazio }\end{array}$ & Positiva & $\begin{array}{l}\text { Ampliação da possibilidade } \\
\text { de comunicação com filhos } \\
\text { e relacionamentos sociais }\end{array}$ & $\begin{array}{l}\text { Referiu apreço pela } \\
\text { psicóloga, maior } \\
\text { discriminação do que } \\
\text { estava se passando consigo }\end{array}$ \\
\hline
\end{tabular}

Do ponto de vista da diversidade inicial das queixas, verificamos que, embora todos os participantes tenham manifestado desejo de ajuda relacionado ao mundo interno e às questões de relacionamentos interpessoais, houve predomínio do primeiro. Estes tipos de queixas não apareceram de forma excludente, apesar dos clientes abordarem prioritariamente alguma delas, houve em cada caso uma diversidade de questões elaboradas.

Uma especificidade dos atendimentos nesta modalidade evidenciou-se no aprofundamento que pôde ser dado a cada caso no que tange à explicitação de angústias que ficaram latentes ou que não puderam ser abordadas (ditas) em um primeiro momento. Na maioria dos casos, a queixa expressa no primeiro dia pôde ser elaborada, surgindo outros aspectos de dificuldades dos clientes. Por vezes, a queixa inicial não expressava o conflito vivido (queixa latente), mas algum sintoma desencadeador (queixa manifesta) da procura por atendimento. Em outros momentos, esta pôde ser melhor descrita pelo cliente com exemplos de situações, resgatando sentimentos que achasse relevante em sua experiência.

A ampliação da queixa e uma primeira compreensão do indivíduo em seu contexto e momento de vida ajudaram o participante a elaborar o que estava vivenciando. Estas elaborações possibilitaram ao cliente pensar novos modos de lidar com as dificuldades (posicionamentos ou perspectivas de análise), caracterizando o aspecto clínico interventivo da triagem estendida. Cabe lembrar ainda que, para alguns, a experiência de compartilhar e contar com um interlocutor presente e interessado foi ponto relevante de alívio psicológico.

Foi frequente a ocorrência de pedido (implícito ou explícito) por ajuda ou orientação pontual. Dentre os casos que tiveram orientação diretiva destacaremos o Participante 3, a fim de explicitar um aspecto interventivo possível em triagem estendida. $\mathrm{O}$ participante apresentava medo (do escuro, 
"de monstros") e ao mesmo tempo reações de imposição e controle: determinava regras para as rotinas, tais como, o lugar ocupado pelos familiares dentro do carro, o lugar de dormir, horários para certas atividades, todos justificados pelo seu medo. Após o acolhimento do sentimento de culpa presente nos pais (pelo acidente aos 8 meses), escuta e identificação de alguns pontos importantes do funcionamento familiar e entrevista com a criança, a psicóloga apontou aspectos trazidos por eles que poderiam estar dificultando um funcionamento mais tranquilo da família. Os pais puderam discutir pontos sobre os quais tinham opiniões divergentes ou em relação aos quais não sabiam como agir, e sobre como poderiam ouvir os desejos do filho na busca de um rearranjo dos limites possíveis. Combinaram entre si algumas novas maneiras de lidar com o filho, ampliando diálogo e entrosamento familiar. Pediram à psicóloga que marcasse a $6^{\mathrm{a}}$ consulta após 15 dias da anterior, para que tivessem tempo para experimentar uma nova rotina, fato decorrido. Relataram que apesar do filho ainda solicitar a presença da mãe ao seu lado antes de dormir, dormia em seu quarto, sem manifestar medo. No último encontro da psicóloga com a criança, esta relatou que seus medos haviam diminuído. $O$ estudo e o acompanhamento, com novas avaliações, poderiam ter aprofundamentos não cabíveis na triagem estendida, em função de morarem distante da USP, o caso recebeu encaminhamento externo.

Além dos já citados aspectos de acolhimento, de primeiras compreensões psicodinâmicas e de intervenções pontuais, o atendimento em triagem estendida possibilitou esclarecimentos sobre diversas temáticas, dentre as quais: o papel e a imagem do psicólogo e da psicoterapia, a disponibilidade psíquica necessária para iniciar atendimento, os tipos de atendimentos psicológicos e alternativas práticas para sua realização, levando em conta fatores como localização geográfica, disponibilidade de tempo e financeira. Podemos citar como exemplo o Participante 4, que não estava disponível, naquele momento, para continuidade de atendimento psicológico. Neste sentido, a triagem estendida possibilita maior amplitude na avaliação dos clientes para encaminhamentos subsequentes.

O contato direto com um psicólogo e o diálogo estabelecido no transcorrer da triagem estendida foram citados por diversos participantes como uma experiência relevante e um modo de vivenciar, ainda que de forma abreviada, o que poderia ser uma psicoterapia, servindo como uma referência de trabalho e contribuindo na decisão quanto ao percurso posterior. $\mathrm{O}$ processo permite que o cliente explicite as expectativas (positivas e negativas) com relação ao trabalho do psicólogo, possibilitando maior segurança quanto ao seu objetivo de iniciar uma psicoterapia. Na medida do possível, a triagem estendida permite que os encaminhamentos sejam realizados com uma participação mais ativa por parte do cliente na definição de como será a continuidade de seu próprio percurso.
Do ponto de vista institucional, houve recepção ou acolhimento imediato da demanda, tendo em vista que os clientes foram atendidos, em sua maioria, no momento em que procuraram pela primeira vez a Clínica. A triagem estendida caracterizou-se como primeiro atendimento possível de forma a lidar, em alguma medida, com a angústia do cliente, possibilitando uma experiência terapêutica. Esta modalidade de atendimento pode ser concluída sem a necessidade de encaminhamento, devido a um amplo leque de razões que incluem desde o fato do processo ser considerado clinicamente suficiente, casos em que os clientes buscam orientações específicas, até situações em que os clientes mostram-se indisponíveis para uma continuidade. Tais finalizações das triagens podem contribuir para a eficiência e otimização do funcionamento do serviço como um todo.

Tendo em vista os aspectos acima descritos, e em concordância com Bonomo e cols. (2002) e Salinas e Santos (2002), verificamos que a triagem estendida cumpre a proposta de realizar uma recepção clínica diferenciada e expandida, além de aprofundar a investigação das queixas, servindo como elemento seletivo à instituição. $\mathrm{O}$ maior contato com o cliente permite realizar um encaminhamento mais adequado, tanto pela clareza que o profissional pode ter sobre sua demanda e possibilidades, quanto pela maior ciência que aquele pode ter em relação a desejar ou não a continuidade do atendimento psicológico. A triagem estendida permite avaliar, em alguma medida, antes de proceder os encaminhamentos, as possibilidades psicológicas de vinculação e adesão a um atendimento, tais como, distância e meios de transportes, visto que nem todos tinham automóvel ou facilidade de acesso à Clínica. Nestes casos, o encaminhamento mais adequado consistiu em dirigir o participante para serviços mais próximos a sua residência ou local de trabalho.

Ressalta-se, por fim, que este modelo de triagem, como qualquer outro atendimento psicológico, versa sobre uma relação particular entre o psicólogo e cliente, produzindo, neste sentido, efeitos e significações que não podem ser generalizados. Do mesmo modo, a compreensão obtida no decorrer da triagem estendida deve ser considerada em sua parcialidade interpretativa.

\section{Considerações finais}

Como se trata de um estudo feito com um pequeno número de participantes, faz-se necessário aprofundamento quanto a vários aspectos. A avaliação da satisfação dos participantes e um follow-up a médio e longo prazo parecem ser essenciais para conferir maior solidez ao desenvolvimento desta modalidade de atendimento. A formação e treinamento de profissionais também constituem questões importantes para a realização desta tarefa, que pode em muito contribuir como forma de atenção à saúde em um contexto carente de recursos nesta área. 


\section{Referências}

Agostinho, M. L. (2003). O porco-espinho, o menino do furacão e outras histórias: Quadros de uma exposição psicanalítica. Dissertação de mestrado não-publicada, Instituto de Psicologia, Universidade de São Paulo, São Paulo, SP.

Aguirre, A. M. B. (1987). Triagem psicológica numa clínicaescola: Funções e características principais [Resumo]. Reunião Anual de Psicologia da Sociedade Brasileira de Psicologia, 17, 277.

Ancona-Lopez, M. (Org.). (1995). Psicodiagnóstico: Processo de intervenção. São Paulo: Cortez.

Ancona-Lopez, S. (2005). A porta de entrada: Reflexões sobre a triagem como processo. In C. P. Simon, L. L. MeloSilva, \& M. A. Santos (Orgs.), Formação em Psicologia: Desafios da diversidade na pesquisa e na prática (pp. 259-270). São Paulo: Vetor.

Arzeno, M. E. G. (1993). Nuevas aportaciones al psicodiagnóstico clínico. Buenos Aires: Nueva Visión.

Bleger, J. (1974). La entrevista psicológica. In J. Bleger, Temas de psicologia: Entrevista y grupos (pp. 9-43). Buenos Aires: Nueva Visión.

Bonomo, S., Dominguez, P., \& Tortorella, A. (2002). Sobre las intervenciones diagnósticas en los diferentes âmbitos. In A. Muniz-Martoy (Org.), Diagnósticos e intervenciones: Enfoques teóricos, técnicos y clínicos en la práctica psicológica (pp. 43-50). Montevideo: Editorial Psicolibros.

Chammas, C., \& Herzberg, E. (2006). Consultas psicológicas: Serviço da Clínica Psicológica Dr. Durval B. Marcondes do Departamento de Psicologia Clínica do Instituto de Psicologia da Universidade de São Paulo [CD-ROM]. In Anais do Simpósio Internacional de Iniciação Científica, 14. São Paulo: Universidade de São Paulo.

Fiorini, H. J. (1978). Teoria e técnica de psicoterapias (C. Sussekind, Trad.). Rio de Janeiro: Livraria Francisco Alves. (Original publicado em 1973)

Guerrelhas, F. F., \& Silvares, E. F. M. (2000). Grupos de espera recreativo: Proposta para diminuir o índice de evasão em clínica escola de psicologia. Temas em Psicologia, 8(3), 313-321.

Hegenberg, M. (2004). Ética e técnica da psicoterapia breve na clínica contemporânea. Tese de doutorado não-publicada, Instituto de Psicologia, Universidade de São Paulo, São Paulo, SP.

Herzberg, E. (1996). Reflexões sobre o processo de triagem de clientes a serem atendidos em clínicas-psicológicaescola. In R. M. L. L. Carvalho (Org.), Repensando a formação do psicólogo: Vol. 1. Da informação à formação (pp. 147-154). Campinas, SP: Alínea.
Herzberg, E. (2007). Gerenciamento informatizado de uma clínica-escola de psicologia. Tese de livre docência nãopublicada, Instituto de Psicologia, Universidade de São Paulo, São Paulo, SP.

Isaco, M. A. S., Gil, C. A., \& Tardivo, L. S. P. C. (2004). Consultas terapêuticas, entrevistas iniciais: Uma proposta de atendimento e acolhida em clínica institucional [CD-ROM]. In Anais do Encontro Latino Americano sobre o Pensamento de Donald Winnicott, 8.

Macedo, R. M. (Org.). (1984). Psicologia e instituição: Novas formas de atendimento. São Paulo: Cortez.

Melo, M. H. S. (1999). Um atendimento psicológico preventivo numa clínica-escola de São Paulo. Dissertação de mestrado não-publicada, Instituto de Psicologia, Universidade de São Paulo, São Paulo, SP.

Melo-Silva, L. L., Santos, M. A., \& Simon, C. P. (Orgs.). (2005). Formação em psicologia: Desafios da diversidade na pesquisa e na prática. São Paulo: Vetor.

Ocampo, M. L. S., \& Arzeno, M. E. G. (1981). A entrevista inicial. In M. L. S. Ocampo, M. E. G. Arzeno, M. Felzenszwalb, \& E. G. Piccolo (Orgs.), O processo psicodiagnóstico e as técnicas projetivas (M. Felzenszwalb, Trad., pp. 23-43). São Paulo: Martins Fontes. (Original publicado em 1979)

Romaro, R., Herzberg, E., Knobloch, F., Paparelli, R. B., Garcia, S. A. F., Gabriades, R. H. C. N., \& Favalli, A. P. (2005). Reflexões e decorrências da participação das clínicas-escola no projeto de prevenção ao suicídio da prefeitura municipal de São Paulo. In C. P. Simon, L. L. Melo-Silva, \& M. A. Santos (Orgs.), Formação em Psicologia: Desafios da diversidade na pesquisa e na prática (pp. 323-340). São Paulo: Vetor.

Salinas, P., \& Santos, M. A. (2002). Serviço de triagem em clínica-escola de psicologia: A escuta analítica em contexto institucional. Psychê, 6(9), 177-196.

Silvares, E. F. M. (Org.). (2006). Atendimento psicológico em clínicas-escola. Campinas, SP: Alínea.

Simon, R. (1989). Psicologia clínica preventiva. São Paulo: EPU.

Souza-Filho, M. L.; Oliveira, J. S. C., \& Lima, F. L. A. (2006). Como as pessoas percebem o psicólogo: Um estudo exploratório. Paidéia (Ribeirão Preto), 16, 253-261.

Tognotti, A., \& Herzberg, E. (2004). Consulta psicológica: Serviço da Clínica Psicológica Dr. Durval B. Marcondes do Departamento de Psicologia Clínica do Instituto de Psicologia da Universidade de São Paulo [CD-ROM]. In Anais do Simpósio Internacional de Iniciação Científica, 12.

Turato, E. R. (2003). Tratado da metodologia da pesquisa clínico-qualitativa. Petrópolis, RJ: Vozes. 
Verthelyi, R. F. (1989). Temas en evaluación psicológica. Buenos Aires: Lugar Editorial.

Wolberg, L. R. (1979). Psicoterapia breve (A. Cabral, Trad.). São Paulo: Mestre Jou. (Original publicado em 1965)

Eliana Herzberg é Professora Associada do Instituto de Psicologia da Universidade de São Paulo.

Débora Chammas é mestranda na área de concentração Psicologia Clínica, pelo Programa de Pós-graduação em Psicologia, do Instituto de Psicologia da Universidade de São Paulo, bolsista FAPESP.

Recebido: 07/06/2008

$1^{a}$ revisão: $21 / 01 / 2009$

Aceite final: 10/02/2009 